\title{
HUBUNGAN KELINCAHAN DAN KESEIMBANGAN TERHADAP HASIL RECEIVE PADA ATLET SEPAK TAKRAW PUTRI PUSLATDA JAWA TIMUR
}

\author{
Amelia Vica Riskita Putri ${ }^{1 *}$, Arif Bulqini², I Dewa Made Aryananda Wijaya Kusuma ${ }^{3}$ \\ ${ }^{1}$ Jurusan Pendidikan Kepelatihan Olahraga, Universitas Negeri Surabaya, Surabaya, Indonesia \\ 2 Jurusan Pendidikan Kepelatihan Olahraga, Universitas Negeri Surabaya, Surabaya, Indonesia \\ ${ }^{3}$ Jurusan Pendidikan Kepelatihan Olahraga, Universitas Negeri Surabaya, Surabaya, Indonesia \\ *vicharezky25@gmail.com
}

(Received: October 2019/Revised: October 2019 / Accepted: November 2019)

\begin{abstract}
ABSTRAK: Teknik Receive digunakan pada saat menerima bola dari serangan-serangan yang diberikan oleh pemain lawan. Receive yang baik akan memudahkan dalam memperoleh poin. Berdasarkan survei yang telah peneliti lakukan di PUSLATDA sepak takraw putri Jawa Timur masih banyak penerimaan bola pertamanya (receive) yang kurang baik. Tujuan dari penelitian ini adalah untuk mengetahui hubungan kelincahan dan keseimbangan terhadap hasil receive pada atlet sepak takraw putri PUSLATDA Jawa Timur. penelitian ini merupakan penelitian non-eksperimen dengan pendekatan kuantitatif dengan menggunakan desain penelitian korelasional, yang melibatkan 10 orang atlet sepak takraw putri PUSLATDA jawa timur sebagai populasi yang akan diteliti. Teknik analisis data yang digunakan yaitu rata-rata (mean), standar deviasi, uji normalitas, uji regresi linear berganda dan koefisien determinasi ( $R$ square). Berdasarkan hipotesis dan analisis data yang telah diperoleh maka dapat diketahui bahwa ada pengaruh antara variabel bebas kelincahan terhadap variabel terikat receive dengan sumbangan evektif yang di berikan sebesar $92 \%$, namun tidak terdapat pengaruh antara variabel bebas keseimbangan terhadap variabel terikat hasil receive , namun secara simultan (bersama) terdapat pengaruh yang signifikan antara varial bebas $(X)$ terhadap variabel terikat $(\mathrm{Y})$ sebesar $88,3 \%$ sedangkan sisanya $11,7 \%$ dipengaruhi oleh variabel lain yang tidak diteliti dalam penelitian ini. Berdasarkan data dan pembahasan dalam penelitian ini maka dapat disimpulkan bahwa terdapat hubungan secara parsial (tersendiri) antara variabel kelincahan terhadap hasil receive akan tetapi tidak terdapat hubungan secara parsial (tersendiri) antara variabel keseimbangan terhadap hasil receive, namun secara simultan (bersama) terdapat hubungan antara variabel keseimbangan dan kelincahan terhadap hasil receive pada atlet sepak takraw putri PUSLATDA Jawa Timur.

KATA KUNCl: Kelincahan, keseimbangan, receive sepaktakraw.
\end{abstract}

ABSTRACTS: The Receiving Technique used when receiving a ball from attacks given by an opposing player. A good thank will give you points. Based on a survey that has been conducted at the PUSLATDA sepak takraw girls in East Java, there are still many who accept the ball of approval (receiving) that is not good. The purpose of this study was to determine the relationship of agility and balance to the results of receive on the soccer takraw athletes of East Java PUSLATDA. this research is non research-experiment with a quantitative approach using a correlational research design, which involved 10 East Javanese PUSLATDA female athletes as the population under study. Data analysis techniques used are the mean (mean), standard deviation, normality test, multiple linear regression test and the coefficient of determination ( $R$ square). Based on the hypothesis and analysis of the data that has been obtained, it can be seen that there is an influence between the agility independent variable on the receive dependent variable with an evective contribution that is given at $92 \%$, but there is no influence between the free balance variable on the receiving variable, but simultaneously (together) there is a significant influence between the independent variable $(X)$ on the dependent variable $(Y)$ of $88.3 \%$ while the remaining $11.7 \%$ is influenced by other variables not examined in this study. Based on the data and discussion in this study, it can be concluded that there is a partial relationship (alone) between the agility variables on the receive results but there is no partial relationship (alone) between the balance variables on 
the receive results, but simultaneously (together) there is a relationship between the balance and agility variable on the receive results on the soccer takraw athletes of East Java PUSLATDA .

\section{PENDAHULUAN}

Sepak takraw adalah olahraga permainan yang dimainkan dengan seluruh anggota badan kecuali tangan, namun olahraga ini lebih identik menggunakan kaki. Olahraga ini menggunakan bola yang terbuat dari rotan, namun untuk kejuaraan nasional dan internasional bola yang biasanya di gunakan terbuat dari pelastik sintetis. Permainan sepak takraw ini dimainkan oleh dua regu atau tim di lapangan persegi panjang yang di tengahnya di batasi net. Salah satu regu dikatakan menang apa bila berhasil memasukkan atau mengembalikan bola sedemikian rupa sehingga bola dapat jatuh di lapangan lawan tanpa bisa dikembalikan.

Permainan sepak takraw memerlukan tingkat kesegaran jasmani yang tinggi. Unsurunsur kesegaran jasmani yang diperlukan dalam permainan sepak takraw yaitu meliputi: koordinasi, kecepatan, kelentukan, kelincahan, dan daya tahan. Selain komponen kesegaran jasmani tersebut, para pemain sepak takraw juga memerlukan keseimbangan yang baik dalam bermain sepak takraw, misalnya untuk sikap menerima bola pertama dari serangan lawan (Hanif, 2015: 28). Seorang pemain sepak takraw agar dapat bermain sepak takraw dengan baik juga memerlukan sebuah keterampilan penguasaan teknik yang baik. Beberapa komponen teknik-teknik dasar dalam permianan sepak takraw yaitu sepakan yang terdiri dari sepak sila, sepak kuda, sepak cungkil, sepak telapak kaki, mengkop, menahan dengan dada, menahan dengan paha, dan menahan dengan bahu (Diktora, 1980: 4) (dalam Hanif, 2015: 27). Sedangkan menurut PB. PSTI $(2005,6)$ (dalam Sulaiman, 2014: 70) "teknik dasar bermain terdiri dari : sepak sila, sepak kuda/kura, sepak simpuh, sepak cungkil, memaha, mendada, kepala, sepak mula (service), smash (kedeng dan gulung), dan tahanan (block)". Dalam bermain sepak takraw banyak teknik yang harus dikuasai oleh seorang pemain agar dapat bermain sepak takraw yang sebenarnya yaitu teknik lanjutan. Menurut Hanafi Dkk (2015: 18) "teknik yang harus dikuasai oleh seorang pemain agar dapat bermain sepak takraw yang sebenarnya dan dapat dilihat seni-seninya bermain sepak takraw di antaranya sepak mula (service), smash gulung, smash kedeng, block, heading, bola pertama (receive)."

Receive atau penerimaan bola pertama merupakan salah satu teknik yang harus dikuasai oleh pemain sepak takraw. Teknik ini digunakan pada saat menerima bola dari serangan-serangan yang diberikan oleh pemain lawan. Menerima bola pertama (receive) merupakan suatu gerak kerja yang tidak kalah penting dari sebuah service yang dilakukan, yang juga merupakan salah satu tantangan yang harus dikuasai oleh pemain, suatu kegagalan dalam receive akan sangat menguntungkan bagi lawan (Hanafi, 2015: 28).

Sesuai penjelasan di atas, maka dapat disimpulkan bahwa receive dalam sepak takraw sangatlah peting, karena receive yang baik akan memudahkan dalam memperoleh poin. Untuk meningkatkan kemampuan atlet dalam penerimaan bola pertama (receive) diperlukan latihan seperti receive dengan raket, receive dengan lemparan dan juga latihan receive dengan memantulkan bola ke tembok (Suwardi, 2015: 16). Namun beberapa bentuk latihan tersebut juga perlu di tunjang dengan komponen-komponen fisik untuk lebih memaksimalkan latihan-latihan tersebut, sehingga atlet perlu mengetahui komponen fisik apa saja yang berhubungan dengan kemampuan receive selain latihan teknik yang telah disebutkan diatas, karena berdasarkan survei yang telah peneliti lakukan di PUSLATDA sepak takraw Jawa Timur khususnya atlet putri masih banyak yang penerimaan bola pertama (receive) masih kurang baik. Suatu prestasi olahraga dapat tercapai, apabila memenuhi komponen seperti: atlet yang sangat potensial, selanjutnya dibina serta diarahkan oleh sang pelatih, sarana dan prasarana latihan yang baik, kebutuhan serta kesejahteraan atlet yang perlu perhatian dari pembina/pengurus induk cabang olahrga, serta adanya try out untuk dijadikan evaluasi hasil pembinaan dan juga yang paling utama yaitu pembentukan program latihan yang mencakup teknik, fisik dan mental bertanding 
(Hanif, 2015: 10). PUSLATDA Jawa Timur adalah suatu pusat latihan atau pembinaan atlet-atlet cabang olahraga yang dinaungi oleh KONI provinsi Jawa Timur dan dipersiapkan untuk membela jawa timur dalam laga Ajang Pekan Olahraga Nasional (PON) yang akan di selengarakan pada tahun 2020 di papua, salah satunya adalah cabang olahraga sepak takraw.

Tujuan dari penelitian ini yaitu, untuk mengetahui adanya hubungan kelincahan dan keseimbangan terhadap hasil receive sepak takraw dan juga untuk mengetahui bagaimana hubungan kelencihan dan keseimbangan dapat terjadi terhadap hasil receive sepak takraw. Manfaat dari penelitian ini yaitu, agar dapat mengetahui hubungan kelincahan dan keseimbagan terhadap hasil receive dalam permainan sepak takraw, serta diharapkan dapat memberikan wawasan dan pengetahun terhadapap peningkatan receive sepak takraw kepada pembacanya.

Berdasarkan pada latar belakang masalah di atas, maka peneliti ingin melakukan penelitian yang berjudul "Hubungan Kelicahan dan Keseimbangan Terhadap Hasil Receive Pada Atlet Sepak Takraw putri PUSLATDA Jawa Timur". Sebagai upaya dalam meningkatkan kemampuan atlit dalam penerimaan bola pertama (receive) dalam permainan sepak takraw. Adapun tujuan lain yang ingin dicapai dalam penelitian ini adalah untuk mengetahui hubungan kelincahan dan keseimbangan terhadap hasil penerimaan bola pertama (receive) pada atlet sepak takraw putri PUSLATDA Jawa Timur.

\section{METODE PENELITIAN}

Penelitian ini merupakan penelitian noneksperimen dengan pendekatan kuantitatif. Penelitian ini di laksanakan pada tanggal 1 juli 2019 di PUSLATDA sepak takraw putri Jawa Timur yang bertempat di kantor dinas pendidikan provinsi Jawa Timur, Jl. Jagir sidoresmo v, sidosermo, Kec. Wonocolo, kota surabaya.

Sampel dalam penelitian ini adalah seluruh atlet sepak takraw putri PUSLATDA Jawa Timur yang berjumlah 10 orang atlet. Penelitian ini menggunakan pendekatan one-shot-model yaitu pendekatan yang menggunakan satu kali pengumpulan data. Pengukuran kelincahan menggunakan ' $T$ ' Drill Test, Pengukuran keseimbangan menggunakan Tes stok stand positional balance. Intrumen pengukuran keterampilan Receive menggunakan Tes keterampilan Receive.

\section{HASIL}

Data yang diperoleh dari penelitian ini membahas tentang hasil penelitian dan pembahasan dari tiga variabel yaitu hasil tes kemampuan kelicahan (X1), kemampuan keseimbagan (X2) dan Hasil receive sepak takraw (Y). Pengelolaan data menggunakan program SPSS (statistical package for the soial sciences) 23, bertujuan untuk mendapatkan hasil data yang benar dan dapat dipertanggung jawabkan. Hasil analisis ini ditunjukkan pada tabel dibawah ini dikaitakan dengan kajian pustaka scara teoritis.

Tabel 1. Rata-rata kelincahan (X1)

\begin{tabular}{ll}
\hline Mean & 10,8150 \\
\hline Standar deviasi (SD) & 1,43179 \\
\hline
\end{tabular}

Berdasarkan tabel 1 dapat diketahui bahwa nilai rata-rata (mean) kemampuan kelincahan yaitu 10,8150 dengan standar deviasi (SD) 1,43179 .

Tabel 2. Rata-rata keseimbangan (X2)

\begin{tabular}{ll}
\hline Mean & 37,7000 \\
\hline Standar deviasi (SD) & 13,26692 \\
\hline
\end{tabular}

Berdasarkan tabel 2 dapat diketahui bahwa nilai rata-rata (mean) kemampuan keseimbangan pada atlet yaitu 37,7000 dengan standar deviasi (SD) 13,26692.

Tabel 3. Rata-rata receive $(\mathrm{Y})$

\begin{tabular}{ll}
\hline Mean & 61,1000 \\
\hline Standar deviasi (SD) & 6,31489 \\
\hline
\end{tabular}

Berdasarkan tabel 3 dapat diketahui bahwa nilai rata-rata (mean) kemampuan receive pada atlet yaitu 61,1000 dengan standar deviasi (SD) 6,31489.

Tabel 4. Uji Normalitas

\begin{tabular}{lcl}
\hline Variabel & Sig & Arti \\
\hline Kelincahan &, 105 & Normal \\
\hline Keseimbangan &, 200 & Normal \\
\hline Receive &, 062 & Normal \\
\hline
\end{tabular}


Journal of Sport and Exercise Science, Vol 2, No 2, 2019 (44-48)

Hubungan Kelincahan Dan Keseimbangan Terhadap Hasil Receive Pada Atlet Sepak

Takraw Putri Puslatda Jawa Timur

Dasar pengambilan keputusan uji shapiro wilk dapat dilihat dari nilai signifikansi dari uji tersebut yang menunjukan apabila nilai signifikansi > 0,05 maka data tersebut dikatakan normal. Sedangkan apabila nilai signifikansi menunjukan < 0,05 maka data tersebut dikatakn tidak normal. Berdasarkan data di atas dapat di ketahui bahwa data dalam penelitian adalah normal.

Tabel 5. Ringkasan Analisis Regresi Berganda (multiples)

\begin{tabular}{llll}
\hline Variabel & $\begin{array}{l}\text { Koefisisen } \\
\text { regresi }\end{array}$ & Thitung & Sig. \\
\hline (Constant) & 111,647 & & \\
X1 & $-4,386$ & $-7,083$ & 0,000 \\
X2 & $-0,083$ & $-1,237$ & 0,256 \\
\hline F hitung & $=26,488$ & & 0,001 \\
R Square & $=0,883$ & &
\end{tabular}

Berdasarkan tabel di atas dapat disimpulkan bahwa :

a) Pengujian hipotesis pertama ( $\mathrm{H} 1)$, diketahui nilai sig untuk hubungan kelincahan (X1) terhadap hasil receive $(\mathrm{Y})$ sebesar $0,000<$ 0,05 dan nilai thitung sebesar 7,083 $>\mathrm{t}$ tabel 2,365 sehingga dapat disimpulkan bahwa (H1) diterima dan ( $\mathrm{HO})$ ditolak atau terdapat hubungan antara variabel kelincahan (X1) terhadap variabel hasil receive $(\mathrm{Y})$.

b) Pengujian hipotesis kedua ( $\mathrm{H} 2)$ diketahui nilai sig untuk hubungan keseimbangan (X2) terhadap hasil receive $(\mathrm{Y})$ sebesar $0,256>$ 0,05 dan nilai $t$ hitung sebesar $1,237<t$ tabel 2,365 sehingga dapat disimpulkan bahwa $(\mathrm{H} 2)$ ditolak dan $(\mathrm{H} 0)$ diterima atau tidak terdapat hubungan antara variabel keseimbangan (X2) terhadap variabel hasil receive (Y).

c) Pengujian hipotesis ketiga (H3) diketahui nilai signifikansi untuk hubungan variabel bebas kelincahan (X1) dan variabel bebas keseimbangan (X2) secara bersama (simultan) terhadap variabel hasil terikat receive $(\mathrm{Y})$ adalah sebesar 0,001 $<0,05$ dan nilai $F$ hitung sebesar $26,488>$ nilai $F$ tabel 4,46 sehingga dapat di disimpulkan bahwa $(\mathrm{H} 3)$ diterima dan ( $\mathrm{HO}$ ) ditolak atau terdapat hubungan antara variabel bebas kelincahan (X1) dan variabel bebas keseimbangan (X2) secara simultan terhadap variabel terikat hasil receive $(\mathrm{Y})$.

maka dari data yang diperoleh secara keseluruhan dapat disimpulkan bahwa ada pengaruh antara variabel bebas kelincahan terhadap variabel terikat hasil receive dengan sumbangan efektif yang diberikan sebesar $92 \%$, namun tidak terdapat pengaruh antara variabel bebas keseimbangan terhadap variabel terikat hasil receive. Namun secara simultan (bersama) terdapat pengaruh yang signifikan antara variabel bebas $(\mathrm{X})$ terhadap variabel terikat $(\mathrm{Y})$ sebesar $88,3 \%$ sedangkan sisanya $11,7 \%$ dipengaruhi oleh variabel lain yang tidak diteliti dalam penelitian ini.

\section{Pembahasan}

Penelitian ini di lakukan pada hari senin, tanggal 01 juni 2019 di lapangan sepak takraw yang bertempat di gor lapangan tenis kantor dinas pendidikan provinsi jawa timur yang beralamat di jalan jagir sidoresmo. Dalam penelitian ini melibatkan 10 orang atlet sepak takraw putri sebagai subyek dalam penelitian dan dua orang pelatih yang membantu mengambil data dalam penelitian ini.

Data yang diperoleh dari penelitian ini membahas tentang hasil penelitian dan pembahasan dari dua variabel bebas yaitu hasil tes kemampuan kelicahan (X1), kemampuan keseimbagan (X2) dan satu variabel terikat yaitu Hasil receive sepak takraw (Y). Berdasarkan hipotesis dan analisis data yang telah diperoleh maka dapat diketahui bahwa ada pengaruh antara variabel bebas kelincahan terhadap variabel terikat hasil receive dengan sumbangan efektif yang diberikan sebesar $92 \%$, namun tidak terdapat pengaruh antara variabel bebas keseimbangan terhadap variabel terikat hasil receive. Namun secara simultan (bersama) terdapat pengaruh yang signifikan antara variabel bebas $(X)$ terhadap variabel terikat $(\mathrm{Y})$ sebesar $88,3 \%$ sedangkan sisanya $11,7 \%$ dipengaruhi oleh variabel lain yang tidak diteliti dalam penelitian ini. Menurut Saputro (2016:39) "kelincahan sangat membantu gerakan sepak takraw kedalam pertandingan, apabila kelincahan yang dimiliki seseorang semakin baik, maka pergerakannya semakin baik pula". Oleh karena itu apabila seorang atlet tidak 
sering berlatih kelincahan maka ia akan kesulitan dalam merubah arah tubuhnya dengan cepat dan menuju daerah tujuannya, sehingga pada akhirnya akan memperkecil kesempatanya untuk menyelamatkan daerahnya dari serangan lawan.

\section{SIMPULAN DAN REKOMENDASI}

Berdasarkan data dan pembahasan dalam penelitian ini maka dapat disimpulkan bahwa terdapat hubungan secara parsial (tersendiri) antara variabel kelincahan terhadap hasil receive akan tetapi tidak terdapat hubungan secara parsial (tersendiri) antara variabel keseimbangan terhadap hasil receive, namun secara simultan (bersama) terdapat hubungan antara variabel keseimbangan dan kelincahan terhadap hasil receive pada atlet sepak takraw putri PUSLATDA Jawa Timur. sehinggah saran yang dapat diberikan dalam penelitian ini yaitu : Mengingat sedikitnya penelitian yang membahas tentang receive sepak takraw sehingga referensi untuk bahan perbandingan masih sangat kurang. Penelitian ini dapat dijadiakan referensi oleh pelatih dalam meningkatkan kemampuan receive pada atlet sepak takraw.

\section{REFERENSI}

Hanafi, Mochamad, Bulqini, Arif dan Hakim, Abdul Aziz 2016. Buku Ajar Sepak Takraw. Surabaya: Adi Buana University press.

Hanif, Achmad Sofyan. 2015. Kepelatihan Dasar Sepak Takraw. Jakarta: PT Raja Grafindo Persada.

Maksum, Ali. 2018. Metodologi Penelitian Dalam Olahraga. Surabaya: Unesa University Press.

Saputro, Puguh Rahmad. 2016. Prediksi Keterampilan Teknik Dasar Bermain Sepaktakraw Berdasarkan Anthropometri Dan Kondisi Fisik (Studi Korelasional Tinggi Badan, Berat Badan, Panjang Tungkai, Kekuatan Otot Tungkai, Koordinasi MataKaki, Kelincahan Dan Fleksibilitas Pada Mahasiswa Pembinaan Prestasi Sepaktakraw Universitas Sebelas Maret Surakarta). Surakarta: Universitas Sebelas Maret Press, (online), (https://digilib.uns.ac.id/ diakses 13/10/2019).
Sulaiman. 2014. Alat Tes Keterampilan Sepak Takraw Bagi Atlet Sepak Takraw Jawa Tengah. Journal of Physical Education, Health and Sport. Vol. 1 (2), 69-76, (Online), (http://journal.unnes.ac.id/nju/index.php/ jpehs).

Suwardi. 2015. Pengaruh Metode Latihan Penerimaan Bola Pertama Dengan Lemparan Dan Menggunakan Raket Terhadap Penerimaan Bola Pertama Pada Atlet PPOP Sepak Takraw Kabupaten Jepara Tahun 2015. Semarang: Semarang University Press. 